This item was submitted to Loughborough's Research Repository by the author.

Items in Figshare are protected by copyright, with all rights reserved, unless otherwise indicated.

\title{
Migration theories: a critical overview
}

\section{PLEASE CITE THE PUBLISHED VERSION}

https://www.routledge.com/products/9781138794313

\section{PUBLISHER}

(c) Routledge

\section{VERSION}

AM (Accepted Manuscript)

\section{PUBLISHER STATEMENT}

This work is made available according to the conditions of the Creative Commons Attribution-NonCommercialNoDerivatives 4.0 International (CC BY-NC-ND 4.0) licence. Full details of this licence are available at: https://creativecommons.org/licenses/by-nc-nd/4.0/

\section{LICENCE}

CC BY-NC-ND 4.0

\section{REPOSITORY RECORD}

O'Reilly, Karen. 2019. “Migration Theories: A Critical Overview”. figshare. https://hdl.handle.net/2134/19442. 
CITATION: O'Reilly, Karen, (2015) '1.MIGRATION THEORIES: A CRITICAL OVERVIEW' in Triandafyllidou, Anna (ed) Routledge Handbook of Immigration and Refugee Studies.

\section{Submitted 29/7/14}

Karen O'Reilly (submitted version)

The role of theory in social science is to provide analytical frameworks through which to examine social phenomena. To a great extent lay, policy, government, and mass media understandings of migration are based on an assumption there is a problem to address, or something unusual to explain. To a social scientist, alternatively, migration is simply another social phenomenon, with related social processes, actions, patterns, arrangements, and outcomes, the examination of which illuminates our understanding of human life. International migration (on which I focus here, although the theories discussed are often also employed in relation to domestic migrations) is a particular challenge to theorists because it has 'nation' at its heart. Despite the drive to explain migration that is given impetus by nation states' demands for monitoring, control and limitation, social scientists study international migration because it has the potential to change individuals and societies in diverse and interesting ways, the potential to exploit, to enrich, to bring about competition, and to engender change. It raises questions about identity, belonging, location, resources, social cohesion and social divisiveness.

Although migration has as long a history as human life itself, there is no doubt that international migration has increased considerably in recent decades, as evidenced in data from the United Nations, the Organisation for Economic Cooperation and Development, the International Organisation for Migration, and numerous other monitoring bodies and statistical agencies. International migration is also in a state of constant flux in terms of shape, form, direction, and content (Papastergiadis, 2000). We could say that international migration is now a normal feature of contemporary societies: a global phenomenon of flows and counter-flows; geographical fluidity rather than population shifts; ongoing daily processes, not unique events. Unsurprisingly, then, the topic has become the focus of a great deal of disciplinary and inter-disciplinary empirical social science from scholars in sociology and anthropology, human geography and demography, politics and international relations, and even cultural studies and the arts. The result is that there is now a wealth of empirical knowledge about diverse flows and outcomes, and an eclectic mix of approaches drawn on in terms of theoretical explanation (Bommes and Morawska 2005: 2). It is this eclectic mix of theoretical approaches to which I now turn, before considering the possibility for a unifying migration theory. I finish by outlining very briefly a potential theoretical framework for migration studies that draws on practice and structuration theories in order to tell practice stories about migration. Practice stories direct us to investigate ongoing processes and the contexts that make them possible, such as with the initial decision to migrate, and then also to follow these narratives through as the initial practices then go on to shape general patterns, arrangements, rules, norms, and other structures in the destination locales in terms of the outcomes of migration (see O'Reilly 2012). In doing so they put people's actions in the context of their historical and contemporary conditions.

\section{Neoclassical economic theories}


Theoretical examinations of migration have focused their attention either on the process of movement or on the settlement process. In terms of the process of movement, economic theories have been predominant, heavily influenced by Ernest George Ravenstein's $(1889,1976)$ attempt to find laws of human behaviour to explain observable patterns over a century of observations in which people tended to move in the direction of densely to less populated areas, poorer to wealthier countries, and from lowwage to higher-wage areas. Ravenstein concluded that favourable and unfavourable economic conditions thus serve to push and pull individuals in predictable directions, and the search for these features of migration has since become a feature of migration studies.

In more contemporary uses of the simple push/pull dichotomy the emphasis on economic factors remains but other factors may also be acknowledged. 'Push' factors that compel people to leave a country of origin can therefore include political oppression, poor living standards, and low economic opportunities. 'Pull' factors, attracting migrants to a different place, may include a demand for labour, the opportunity for higher living standards, but also political freedom. Where this neoclassical, supply and demand, economic approach is used it relies, albeit often implicitly, on a rational choice model of human behaviour, in which supposedly rational, profit-maximising individuals weigh up the costs and benefits of various options before making their decisions. Barry Chiswick (2000), for example, uses the methodology of economics (testing theoretical models against quantitative empirical data) to address the question 'who moves and who does not' by comparing motives, ability and skills; that is by looking at the supply side of migration. He concludes that all migrants (especially economic migrants) tend 'on average, to be more able, ambitious, aggressive, entrepreneurial, healthier ... than similar individuals who choose to remain in their place of origin' (p64). That is, migrants favourably self-select.

From a macro perspective, this economic view of migration, that is apparently built on an understanding of individual agency, locates the universal human being within the global supply and demand for labour in universal markets, in which countries with more work, higher wages and fewer workers attract workers from countries with lower wages and less work. Push/pull theories of migration thus support a politically liberal view, positing the notion that if left to work naturally (relying on the actions and choices of the rational individual) then the open migration market should achieve its own equilibrium, as the poorer move to richer countries and the crowded move to less populated areas. In fact, the economic push and pull model of migration overlooks a host of factors that influence moves, including historical relations, family and community dynamics, the role of intermediaries encouraging migration by arranging passage, and of course the role of states in recruiting labour, granting (or withholding) permits, establishing policies on refugees and asylum seekers, and determining citizenship rights.

\section{New economic and dual/segmented labour market theories}

New economic theories and dual/segmented labour market theories are refinements of rational-choice economic theories explaining the process of movement. Dual/segmented labour market theories refer to the dualistic or segmented nature of economies in the developed world. Here it is assumed that the majority of work (the primary labour market) is secure, regular and well-paid, but the nature of the way in which these economies works means that, from time to time, there are bouts of temporary, or seasonal, insecure and less well-paid work. These jobs, in what is known here as the secondary labour market, often need filling at short notice, tend to be avoided by locals because of their insecure nature, and thus attract temporary labour from abroad. The theoretical explanation for migration in this case thus gives causal primacy to markets, albeit these are assumed to act through the rational choice of 
actors. The approach is uncritical, simplistic and politically liberal: industrial economies are portrayed as having an 'insatiable thirst for cheap labour' (Gonzalez and Fernandez, 2003: 46), while migrants are portrayed as free to exploit destinations for their own short-term gain. The approach ignores the fact that migrant labourers often tend to settle, and to 'segment' into long-term insecure and low-paid work. It also overlooks the fact that many migrants move on their own initiative and create jobs that would not otherwise exist.

New economic theories of migration continue to acknowledge the central role of (mainly economic) push and pull factors in determining the agency of individuals, but they also recognise the many intervening variables that facilitate and hinder migration. In these cases, migration research draws attention to the role played by the wider networks of family and friends who help migrants to move and to settle through financial and emotional support, and the middlemen, brokers, contractors and agencies that promote and facilitate migration. But these tend to be examined in the context of their role in hindering or enabling the result of the pushes and pulls. Individual feelings and emotions, the angst that accompanies difficult decisions about whether or not to leave one's home, family and friends, and the ways in which these attitudes and expectations have been shaped over time by culture, communities and communication, are generally overlooked. Examining the reasons for what he calls the United States' crisis in immigration, Phillip Martin (2004: 99), for example, says push and pull factors are 'like battery poles; both are necessary to start a car or a migration stream. Once started, intervening variables such as networks influence who migrates where'. If a government wants to stay in control, he suggests, it must deal with all of these three aspects. He does not discuss how they interact. For Arango (2004: 23), the new economics of migration is little more than 'a critical, sophisticated version of neoclassical theory'.

Few empirical studies of the process of migration overtly adhere to a specific theory or approach, and few suggest that the action is the result of unfettered decisions driven by calculations of pushes and pulls. Yet, there is often an emphasis on agents acting out a conscious choice, or on individual decisionmaking, as witnessed in studies that examine migration in terms of a search for a better way of life, for community, for work, or even for family reunification. There may be no analysis of how systemic changes and structural forces are understood and interpreted by agents.

\section{World systems theory}

World systems theory, alternatively, focuses more on wider systems than on individuals agents. Here the world itself can be viewed critically as a single capitalist system in which poorer nations, the periphery, provide a constant supply of cheap labour to support the powerful and wealthy nations at the core of the system (Wallerstein 1974). It is an approach on which many contemporary critiques of global capitalism are based, and it explains the poverty of poorer nations in terms of historical relations of power, dependency and debt. Drawing from Marxist political economy, it emphasises global inequalities and views migration as a central feature contributing to the perpetuation of the system. It is not in opposition to the push/pull approach, but rather takes a critical and global view to explain the actions of individuals from a structural perspective. Here, migration is just another element in the domination of the Third World and works hand in hand with military and economic control (see Portes and Walton 1981, Sassen 1988). The approach was particularly prominent during the 1960s and 70s, when the mass migrations that reversed former colonial routes were the ones causing most consternation and academic interest. Gonzalez and Fernandez (2003) fear that world systems theory reifies the 'agency' of 
Third-World elites, thereby according them a higher degree of autonomy than is justified. Faist (2010), alternatively, draws attention to the economic bias in world systems theory, which tends to overlook political and cultural processes. A theory of practice, as discussed below, with its emphasis on wider systems as relevant to and made by agents themselves (including migrants) instead enables migration researchers to question how such power is enacted and embodied, perpetuated, strengthened, or challenged and transformed.

\section{Migration systems and networks theory}

The theories outlined above offer somewhat simplistic explanations for the process of movement, with an emphasis on labour migration and on a one-off move to a new destination. They also favour either a structural or an action-centred approach, without theorising the intricate relationship between structures and agency. They are not useful for complex migration processes that take place, become consolidated, change in nature and shape, and emerge anew over time. Castles and Miller (2009) contend that interdisciplinary research should be employed by migration scholars to examine the role of both social structures and individual actions, as well as the intermediate level of agents and intermediaries in the decision-making processes and the outcomes of migration. But rather than develop a macro-theoretical framework for understanding these complex processes, they suggest that complexity is framed within migration systems or networks. Migration systems and networks theory thus acknowledges that moves tend to cluster, can be circular, and take shape within wider contexts and systems. Understanding migration processes thus involves moving out from the individual to the wider and interconnected sets of circumstances - the wider system or network - within which an individual agent is located. Castles and Miller (2009) use the example of Mexican migration to the US to illustrate how this is part of the longer history (and, therefore, wider system) of US expansion into the south-west in the early twentieth century. It would be interesting to continue this system analysis and to now include the retirement migration of US citizens to Mexico (Kiy and McEnany 2010). This is a good way to start to think beyond the individual small-scale decisions of migrants. Practice stories, discussed below, go further than migration systems, providing the meta theoretical framework within which we can understand the production and reproduction of structures through actions and practices, in communities and networks.

\section{Assimilation and multiculturalism}

In terms of processes of settlement, the main concern for early migration scholars, like the policy makers and government agents they often hoped to inform, was to examine the extent to which migrants became assimilated into the culture and (national) society to which they had moved. Here, it was often assumed that migration was a threat to the purported cultural homogeneity and thus the stability of the nation state, and migration was theorised in terms of assimilation and adaptation on the part of the migrant. Clearly, the assumption was that the migrant should be doing the adapting and assimilating, not the previously settled community. The problem here is that in many cases indigenous groups were also perceived as unassimilated minority groups, and so migrants became seen as minorities and minorities as outsiders. Assimilation as a term comes with a great degree of baggage and it is difficult to use it without at least appearing to make value-judgments. As Bagby (2009: 474) contends, there remains a general, lay, theory that 'immigrants and their children will inevitably assimilate into American culture and move away from their 'traditional' culture, as they become integrated into the socio-economic life of America.' In such cases, a very different group, protecting its difference and its values can be portrayed as extremist, hostile or dangerous. 
As time passed, governments and policy makers became accustomed to the idea their migrants might settle permanently and that it is more morally acceptable as well as practically achievable to accept and tolerate difference. They thus started to pursue what Cohen (2006:6) refers to as the rather more nebulous goals of 'multiculturalism', 'pluralism', or 'rainbow nationhood'. Coincidentally, migration scholars began to examine processes of settlement with reference to multiculturalism as a theoretical tool to aid empirical and critical research. Here, theoretical treatises analyse the extent to which groups can exist side by side, retaining some elements of their distinct cultures, while sharing the same rights and responsibilities. Studies will also critically examine the role of multiculturalism in identity, social cohesion and conflict. In the US, for example, Portes and Zhou (1993) have theorised a segmented form of assimilation that describes the ways in which, over time, Mexican migrants have been assimilated into marginal segments of society rather than into the mainstream. Assimilation and multiculturalism thus both take the form of policies and actions for academics to theorise (eg Kymlicka 2012), as well as theoretical frames for understanding outcomes.

\section{Migration flows and mobilities}

Early migration theories and approaches often assumed migration was linear, and studies centred on labour migration to the exclusion of other forms. More recently, scholars are developing new concepts and frameworks with which to understand non-linear, circular, and temporary flows and are including diverse types of migrant such as affluent migrants and asylum seeking migration. Studies examining the globalisation of migration, for example, include analyses of the historical and global developments affecting and affected by (Massey et al 1998). Transnationalism is a relatively new concept that is used to enable the theorising of processes that travel to and fro across borders, and between and beyond nation states. Transnationalism is a call to researchers not to ignore things outside of the state, not to be 'methodologically nationalist' (Wimmer and Glick Schiller 2002). Finally, the concept of mobilities (Urry 2007) introduces the notion of flows and continual movement to migration studies and thereby raises a further challenge to the hitherto excessive attention paid to North America and Europe over other parts of the world, and the fixation on immigration. But the world has not become one characterised by movement - still the vast majority of people never migrate, even temporarily - and so other theorists are drawing attention to the existence of counter-flows to globalization and restrictions to movement (Kivisto 2001; Faist 2000). There are many other approaches too. Theorising a post-colonial relationship in migration, for example, involves drawing attention to established relations of inequality, economic ties based on prior appropriation, continuing exploitation, and/or cultural links informed by previously unequal relationships. Finally, there has been a tendency to perceive migration in terms of the male pioneer blazing a trail to new destinations, followed eventually by the female partner and family (Harzig 2001). But the migration of women has been on the increase and it is not always, by any means, related to male migration in a straight-forward way. A feminist-informed migration studies has taken the notion of gender as its focus, and has begun to explore the roles migration plays in shaping social orders and geographies of inequality.

\section{A Unifying Migration theory?}

A number of migration scholars are now contributing to debates about the need for a single unifying theory or theoretical framework for migration. In Worlds in Motion, Douglas Massey (1998) and his colleagues reviewed and evaluated the broad range of theoretical work in the field of international migration for its efficacy in understanding the world's principal migration systems. They concluded that, rather than attempt to devise an overarching theory of migration, a synthesis of theoretical approaches 
can provide an integrated approach to the study of international migration as a whole. But a synthesis no more provides a framework for the study of social processes than do the approaches separately employed, and crucial elements such as culture and structuration processes can be ignored as a result (Morawska 2001). Furthermore, such a synthesis can incorporate serious contradictions, such as those between rational choice theory and world system's theory (Bakewell 2010).

Later, Stephen Castles (2007) bemoaned the fact that migration studies and their theories have drifted from mainstream sociology and from the insights offered by social theory more broadly understood. He wishes to encourage migration scholars to embed their understandings of migration within an understanding of wider social transformations. However, both he (Castles 2010) and Alejandro Portes (2010) have more recently argued that a search for a framework or unifying theory for migration scholars is unnecessary. In his analysis of migration and social change, Portes (2010) is at pains to point out that social theory itself is adequate in understanding social change without the need for a specific theoretical approach for migration. This is partly because: 'Modern states, in particular, are sufficiently powerful to ensure that migration-induced change does not get out of hand and certainly that it does not challenge the core cultural and structural pillars of society' $(2010 ; 1549)$.

Several theorists (eg. Goss and Lindquist 1995; Moraswka 2001) have identified the key problem for coherent understanding of migration processes as being the inability to properly theorise the interaction between structure and agency rather than treat these separately. Migrants make choices but not in circumstances of their own choosing and, having migrated, they change societies in unintended ways that then create new circumstances for future migrants. There are now diverse attempts to draw attention to migration as a structured and structuring process (especially Moraswka 2001, 2009). Bakewell $(2010 ; 1670)$ contends that 'theories of migration have tended to skirt around the problem of structure and agency', either paying too little or too much attention to individual choices. He offers a critical-realist critique of the inherent dualism in structuration as a way out the structure-agency impasse and as a framework with which to deal with methodological dualism. Bakewell suggests that this approach will raise all sorts of challenges for methodology, but is unable to fully explicate how his theoretical approach is operationalised in empirical work.

It is that last challenge, combined with a wish to draw from social theory for migration studies, that Karen O'Reilly (2012) has taken up in her book, International Migration and Social Theory. The meta theoretical framework outlined in this text is informed by strong structuration theory (Stones 2005) and the goal is to tell 'practice stories' of migration; that is, to describe some of the processes in a given migration in such a way as to respect the creative and processual nature of social life and to reveal the structuration processes involved as social life unfolds.

Structuration theory was a social theory of practice proposed by Anthony Giddens (1984). Giddens insists that social life is neither the outcome of individual actions nor determined by social structures. Instead, social structures limit what people can and cannot do, what they even try to or wish to do, but agents do have some free will; and the very social structures that enable or constrain in some situations are made and remade by individuals in the process of their acting (or their agency). For Giddens, agency and structure are a duality - always interdependent and interrelated. In a similar way, Pierre Bourdieu (1977; 1990) argued that people's tastes and preferences, choices, desires and actions cannot be separated from structural constraints, because people internalize what is possible for them. 
Bourdieu proposes the concept of practice as a way of thinking through those same processes that Giddens refers to as structuration; that is, the making and acting out of daily life. His notion of the practice of social life draws on the concept of habitus. Very crudely, habitus refers to the dispositions, habits, ways of doing things, ways of thinking, and ways of seeing the world that individuals acquire, singly and in groups, as they travel through life. They are therefore structures that have become internalized and embodied, and are acted out by people. People are always in practical relations to the world and practices (what we do) are therefore reasonable (sensible, plausible) adjustments to the future rather than rational calculations or the product of identifiable plans.

Rob Stones (2005) has developed a stronger version of structuration theory that builds on the work of Giddens. Stones draws attention to the situational knowledge that actors have about the conditions within which they find themselves at any given time. He emphasizes both the role of external structures - the networks, relationships, hierarchies and resource distributions - and the conjuncturally-specific knowledge a given actor has of this terrain (linked, of course, to the actor's ability to think and act differently, to plan a different future through migration, for example). Furthermore, Stones emphasizes the general nature of habitus, which he sometimes calls general dispositions indicating they are not tied or expressly linked to specific situations but have to adapt to its contingencies. These concepts enable a closer examination of how structure and agency combine dynamically in producing actions such as migration (O'Reilly et al 2014).

O'Reilly's practice stories approach elaborates the above with some insights from other authors. The work of Mustafa Emirbayer and Ann Mische (1998) is used to remember that individuals retain the ability to imagine different ways of living, and different ways of doing things, even if these sometimes seem impossible. It is this distinctive aspect of human agency that gives actors the power to (sometimes) change things. Secondly, she uses insights from Jean Lave and Etienne Wenger's (1991) description of communities of practice and Wenger's (1998) concept of situated learning. Communities of practice are any social group (family, community, work mates, social club, a partnership) that comes together and has to work out how to get on together. A community of practice is a good way of thinking about the level in-between laws and rules, on the one hand, and free choice, on the other hand. It is in their communities of practice that individuals learn what the rules of 'the game' are and how much they have to adhere to them. It is from people with whom we come into contact that we get ideas about how things might be different, and who has the power to change what. Lave and Wenger call this 'situated learning'. The approaches discussed above may each have a role to play in helping elaborate given practice stories about given migration processes (though some may be incompatible). The use of practice stories is to provide a social science framework to understand what is undeniably a structured and structuring process.

\section{Conclusion}

To conclude, contemporary migration theories and perspectives recognise the existence of diverse flows and counter-flows, examine immigration and emigration within wider systems and networks, are able to theorise movements, mobilities and processes, rather than acts and effects, and are more likely than in the past to consider transnational phenomena, and the role of women in migration. There is more emphasis than previously on the many macro, micro and meso level factors that impinge on an agent's experience of the whole migration process (including those who don't move but can still be affected). And there have been attempts to construct broad-brush theories or a synthesis of approaches 
for a more unified approach to migration. The most comprehensive theoretical framework suggested is the macro-theoretical framework of practice theory, with the telling of practice stories for migration. This framework approach has implications for methodology in migration studies. In order to understand the structuration processes involved in migration both studies of broad scope (macro, historical studies) and close, intimate studies of daily life are required. And these approaches need to work together. Studies of broad scope are meaningless without the analysis of the role of structures in the practice of daily life, in the context of historical relations and contemporary machinations.

\section{References}

ARANGO, J., 2004. Theories of International Migration. In: D. J OLY, ed, International migration in the new millennium : global movement and settlement. Aldershot ;

Burlington, Vt.: Ashgate, pp. 15-35.

BAKEWELL, O., 2010. Some Reflections on Structure and Agency in Migration Theory, Journal of Ethnic and Migration Studies, 36(10): 1689-1708

BAGBY, I., 2009. The American Mosque in Transition: Assimilation, Acculturation and Isolation. J ournal of Ethnic and Migration Studies, 35(3), 473-490.

BOMMES, M. and MORAWSKA, E.T., eds, 2005. International migration research : constructions, omissions and the promises of interdisciplinarity. Aldershot: Ashgate.

BOURDIEU, P., 1990. The logic of practice. Cambridge: Polity.

BOURDIEU, P., 1977. Outline of a theory of practice. Cambridge: Cambridge University Press.

CASTLES, S., 2007. Twenty-First-Century Migration as a Challenge to Sociology. Journal of Ethnic and Migration Studies, 33(3), pp. 351-371.

CASTLES, S., 2010. Understanding Global Migration: A Social Transformation Perspective. Journal of Ethnic and Migration Studies, 36(10), pp. 1565-1586.

CASTLES, S. and MILLER, M.J., 2009. The age of migration : international population movements in the modern world. 4th edn. Basingstoke: Palgrave Macmillan.

CHISWICK, B., 2008. Are Immigrants Favourably Self-Selected? In: C. BRETTELL and J.F. HOLLIFIELD, eds, Migration theory : talking across disciplines. 2nd edn. London: Routledge, pp. 61-76.

COHEN, R., 2006. Migration and its enemies : global capital, migrant labour and the nation-state. Aldershot: Ashgate.

EMIRBAYER, M. and MISCHE, A., 1998. What Is Agency? American J ournal of Sociology, 103(4), pp. 962-1023.

FAIST, T., 2000. The volume and dynamics of international migration and transnational social spaces. Oxford: Clarendon.

GIDDENS, A., 1984. The constitution of society : outline of the theory of structuration. Cambridge: Polity.

GONZALEZ, G.G. and FERNANDEZ, R.A., 2003. A century of Chicano history : empire, nations, and migration. New York ; London: Routledge. 
HARZIG, C., 2001. Women migrants and global and local agents. In: P. SHARPE, ed, Women, gender, and labour migration : historical and global perspectives. London: Routledge, pp. 15-28.

KIVISTO, P., 2001. Theorizing Transnational Immigration: A Critical Review of Current Efforts. Ethnic and Racial Studies, 24(4), pp. 549-577.

KYMLICKA, W., 2012. Multiculturalism: Success, Failure and the Future. Washington, DC: Migration Policy Institute.

KIY, R. and MCENANY, A., 2010. Civic engagement, volunteerism, and charitable giving: Americans retired in Mexican Coastal Communities. National City, CA: International Community Foundation.

LAVE, J. and WENGER, E., 1991. Situated learning : legitimate peripheral participation. Cambridge: Cambridge University Press.

MARTIN, P.L., 2004. The United States: Benign Neglect Toward Immigration. In: W.A. CORNELIUS, P.L. MARTIN and J.F. HOLLIFIELD, eds, Controlling Immigration. A Global Perspective.pp. 83-99. Stanford CA: Stanford University Press, pp.83-99

MASSEY, D.S., ARANGO, J., HUGO, G., KOUAOUCI, A., PELLEGRINO, A. and EDWARD TAYLOR, J., 1998. Worlds in motion : understanding international migration at the end of the millennium. Oxford: Clarendon Press.

MORAWSKA, E., 2001. Structuring Migration: The Case of Polish Income-Seeking Travelers to the West. Theory and Society, 30(1), pp. 47-80.

MORAWSKA, E.T., 2009. The sociology of immigration : (re)making multifaceted America. Basingstoke: Palgrave Macmillan.

O’REI LLY, K., 2012, I nternational Migration and Social Theory. Basingstoke: Palgrave Macmillan.

O'REI LLY, K., STONES, R. and BOTTERILL, K. (2104) 'Lifestyle migration in East Asia: Integrating ethnographic methodology and practice theory' in Sage Research Methods Cases, Sage Publications Ltd (viewed 29/07/14), DOI: http://dx.doi.org/10.4135/978144627305013509192

PAPASTERGIADIS, N., 2000. The turbulence of migration : globalization, deterritorialization, and hybridity. Cambridge: Polity Press.

PORTES, A., 2010. Migration and Social Change: Some Conceptual Reflections. J ournal of Ethnic and Migration Studies, 36(10), pp. 1537-1563.

PORTES, A. and WALTON, J., 1981. Labor, class and the international system. New York ; London: Academic Press.

PORTES, A. and ZHOU, M., 1993. The New Second Generation: Segmented Assimilation and Its Variants. 530, pp. 74-96.

RAVENSTEIN, E.G., 1976. The Laws of Migration. New York: Arno Press.

RAVENSTEIN, E.G., 1889. The laws of migration. Journal of the Statistical Society, 52, pp. 214-301.

SASSEN, S., 1988. The mobility of labor and capital : a study in international investment and labor flow. Cambridge: Cambridge University Press. 
STONES, R., 2005. Structuration theory. Basingstoke: Palgrave Macmillan.

URRY, J., 2007. Mobilities. Cambridge: Polity.

WALLERSTEIN, I.M., 1974. The modern world system. New York ; London: Academic Press.

WIMMER, A. and SCHILLER, N.G., 2002. Methodological Nationalism and Beyond: NationState Building, Migration and the Social Sciences. Global Networks, 2(4), pp. 301-334. 